\title{
UMA ARGUMENTAÇÃO PELA ORQUESTRAÇÃO DAS VOZES NUMA ENTREVISTA OU COMO REBATER UMA DOXA MÉDICA COM SUAVIDADE
}

\section{Marie Carcassonne}

Resumo: Uma forma de tensão reside em todos nós para explicar a origem de uma doença, particularmente entre o discurso médico e os demais discursos (CLAVREUL, 1978). No presente artigo, essa tensão é mostrada por meio da identificação de diferentes vozes numa entrevista de pesquisa em psicopatologia, desvelando-se o modo como a orquestração de vozes por uma entrevistada desempenha a função de argumentação e de produção positiva de si. $\mathrm{O}$ artigo apresenta o quadro de análise do discurso empregado, que é um quadro dialógico (VOLOCHINOV, 1977 [1929]), interativo e enunciativo, com forte mobilização da noção de movimento discursivo e interpretativo (FRANÇOIS, 1989; SALAZAR, 2008). Para explicar a origem de seus distúrbios de comportamento alimentar, a "voz pessoal" (assumida no nível da enunciação de forma branda, porém claramente atualizada) da entrevistada entra em tensão com uma voz que revela uma forma de doxa médica; isso altera a assimetria social esperada numa interação entre médico e não médico (MARKOVÀ \& FOPPA, 1991). A orquestração desta polifonia pela entrevistada é considerada como o exercício de um papel de reposicionamento social no espaço de suspensão pontual permitido na e pela entrevista. Por fim, os movimentos identificados aparecem como lugares discursivos e sociais.

Palavras-Chave: Dialogismo. Argumentação. Discurso médico. Entrevista.

Abstract: A form of tension lives in everyone to explain the origin of a desease, in particular between medical discourse and other types of discourse (CLAVREUL, 1978). In this paper, the location of various voices in a research interview shows this tension. One discovers the way in which the orchestration of the voices by a person interviewed plays a function of argumentation and positive production of oneself. The paper first presents the framework of discourse analysis, namely a dialogical (VOLOCHINOV, 1977 [1929]), interactionnel and enunciative framework, with a strong mobilization of the concept of discursive and interpretative movement (FRANÇOIS, 1989; SALAZAR, 2008). To explain the origin of its aeating desorders, a personal voice (assumed at the enunciative level in a low way but however clearly updated) of the interviewed enters in tension with a medical doxa voice; and this modifies social asymmetry expected in an interaction between physician and nonphysician (MARKOVÀ \& FOPPA, 1991). The orchestration of this polyphony by the interviewed is in conclusion considered as playing a role of social repositioning in the space of suspension allowed in and by the interview. Spotted movements appear in fine as discursive and social places.

Keywords: Dialogism. Argumentation. Medical speech. Interview.

i Doutora em Psicologia pela Université Paris 5. Professora e pesquisadora da Université ParisDauphine, França. Membro do Institut de Recherches Interdisciplinaires en Sciences Sociales (IRISSO). E-mail: marie.carcassonne@dauphine.fr 
EID\&A - Revista Eletrônica de Estudos Integrados em Discurso e Argumentação, Ilhéus, n. 11, jan/jun.2016.

\section{Introdução}

A orquestração polifônica das vozes - no sentido volochino-bakhtiniano1 do termo, ou seja, no sentido em que nenhuma das vozes domina o outro no discurso - será aqui questionada a partir de uma entrevista de pesquisa em psicopatologia. Essa entrevista ocorreu entre um médico, psicanalista e pesquisador, e uma jovem mulher de aproximadamente trinta anos de idade (F.) que foi anoréxica durante vários anos e teve a oportunidade, ao longo de várias psicoterapias, de refletir sobre seu caso e, em particular, sobre a origem de sua doença. Essa entrevista é permeada de ponta a ponta por uma tensão entre a voz do discurso médico e outros tipos de vozes menos especializadas para explicar a ocorrência dos distúrbios do comportamento alimentar. É característico de uma atitude descrita por Clavreul (1978) como sendo a de todos nós diante da esfera do discurso médico, o qual no colocaria numa posição subjetiva dividida: todos se lhe submeteriam sem, no entanto, aceitar a idéia (que ele afirmaria poder se perpetuar) segundo a qual "o médico (ou o chefe) sabe melhor do que você o que lhe convém para o seu bem” (1978, p. 11).

Assim, o plano do texto se organiza, inicialmente, com a apresentação do nosso quadro de análise do discurso (em particular as noções de movimento e de lugares) e, após isso, desenvolveremos certos aspectos teóricos que permitem a identificação das fontes (origem) das "vozes". Em seguida, em consonância com os dois primeiros pontos, diversos trechos da mesma entrevista são comentados, visando as funções argumentativas e sociais que desenvolvem essas vozes no cenário da entrevista.

\section{Dialogismo, movimento (discursivo e interpretativo) e lugar (discursivo e social)}

Nosso quadro de análise adota, como pano de fundo, determinados fundamentos da sociologia cognitiva (CICOUREL, 2002) que propõe ligar a análise do contexto no seu sentido amplo (organizacional, institucional, cultural) à análise do contexto no seu sentido estreito (analisado a partir das interações locais por uma abordagem de inspiração conversacional e etnometodológica), insistindo numa modelagem recíproca dos contextos nos sentidos amplo e estreito. Nossa abordagem se aproxima também de

'Dentro da terminologia do círculo de Bakhtin, quando as vozes aparecem em pé de igualdade e não são "hierarquizáveis" (como BAKHTIN, 1970 [1963] destacou a respeito dos romances de Dostoievski), elas são levadas a uma forma peculiar de dialogismo, denominada "polifonia". Destaquemos, no entanto, que é difícil considerar uma polifonia absoluta das vozes, sem qualquer domínio de nenhum tipo. 
EID\&A - Revista Eletrônica de Estudos Integrados em Discurso e Argumentação, Ilhéus, n. 11, jan/jun.2016.

determinados fundamentos da psicologia sociocultural (ROGOFF, 1990; COLE, 1994; WERTSCH, 1991), oriundos dos desdobramentos das ideias de Vygotski (1985 [1934]), com as quais o pensamento de Volochinov e Bakhtine apresentam aproximações notáveis².

Nosso método de análise destaca em primeiro plano a idéia de que existem significados ligados aos modos de encadeamento dos enunciados, aos "movimentos" do discurso (FRANÇOIS, 1984; SALAZAR, 1999; CARCASSONNE, 2006, 2008, 2010, 2011, 2015³), noção que vamos agora explicitar.

\subsection{Dialogismo e movimentos (discursivos e interpretativos)}

Os movimentos discursivos estão necessariamente ligados aos movimentos interpretativos daquele que os identifica. O sentido "se move", ou melhor, "se desenha" (FRANÇOIS, 1994, p. 34) entre enunciados ou sequências bem delimitadas, uma vez que o receptor os coloca em relação (de forma mais ou menos obrigatória ou facultativa em função e um dado contexto). Os movimentos identificados podem corresponder a movimentos de temas, de categorias (enquanto aspecto mais local de um mesmo tema), de modos enunciativos (passar, por exemplo, de um discurso ancorado enunciativamente a um discurso desancorado), de fontes enunciativas, de tipos de discurso (passar, por exemplo, de uma argumentação para uma narração) etc. O sentido se desenha também na maneira como o receptor pode colocar em relação esses enunciados ou sequências com o contexto (amplo ou estreito) como suas expectativas ligadas ao gênero ${ }^{4}$ do referido discurso.

\footnotetext{
${ }^{2}$ Vygotski insistiu sobre a importância da interação com o outro no desenvolvimento cognitivo do indivíduo: sua perspectiva está em sintonia com os dois autores russos, ainda que esses dois autores não fossem conhecidos dele à época. A psicologia sociocultural concebe os processos cognitivos (inclusive as narrativas de si mesmo) como (i) distribuídos através dos membros de uma comunidade e (ii) circulando através da cultura sob a influência simultânea das interações ocorridas localmente e dos enquadres socioculturais de uma época. Markovà desenvolveu mais globalmente em psicologia social o conceito de "dialogicidade" como "a capacidade do Ego em conceber e compreender o mundo na perspectiva do Alter e criar realidades sociais na perspectiva do Alter" (2003 [2007]), p. 288).

3 Esse artigo retoma, sinteticamente, as diferentes publicações e, em particular, a de 2010.

${ }^{4}$ A noção de "gênero" é aqui considerada no sentido de Bakhtine, que a descreveu como cada "esfera" da atividade humana "[...] comporta um repertório de gêneros de discursos que vai se diferenciando e se amplificando na medida em que se desenvolve e se torna complexa a referida esfera" (BAKHTINE, 1984, p. 265): os "gêneros" do discurso correspondem a tipos relativamente estáveis de enunciados na medida em que são ligados a uma prática social e/ou uma atividade. Eles são oriundos de modelos historicamente constituídos que "orientam" (SCHNEUWLY, 1994, p. 160) nos processos de recepção e, sobretudo de produção dos discursos. Senão, "a troca verbal seria praticamente impossível” (Ibid., p. 285).
} 
EID\&A - Revista Eletrônica de Estudos Integrados em Discurso e Argumentação, Ilhéus, n. 11, jan/jun.2016.

Todo movimento de discurso identificado por um receptor no nível da produção é, portanto, necessariamente um movimento interpretativo proposto pelo receptor-analista. Essas duas vertentes (produção/recepção) fazem o recorte, sem totalmente se sobrepor em uma análise em termos "dialogal/dialógica" (BRES, 2005, p. 49): ou seja, permitem estabelecer, de um lado, laços entre os enunciados co-produzidos pelos interlocutores na situação ("dialogismo interlocutivo"), e, de outro lado, laços com os discursos oriundos de esferas dialógicas anteriores ("dialogismo interdiscursivo").

A dimensão do dialogismo interlocutivo é mais complexa do que parece, como o demonstram Bres \& Nowakowska (2006): ela implica uma modulação da fala do entrevistado em função da imagem que ele projeta de seu interlocutor ou de seus interlocutores (de seus conhecimentos, seu papel, etc.). Essa antecipação incessante da resposta que o locutor imagina por parte de seu interlocutor molda, por sua vez, a de seu interlocutor. De maneira mais ou menos consciente, sempre ocorre, em todo diálogo, uma forma de "préocupação" (CLOT, 1999) dos lugares discursivos, em função das representações do papel de cada um.

O processo do dialogismo interdiscursivo ocorre antes mesmo da "mise en mots" (FRANÇOIS, 1994)5, a lembrança dos eventos vividos não sendo apenas "transformado" pelas leituras ou narrativas escutadas (interdiscursividade), mas também pelo próprio processo da memória que não registra os eventos vividos de maneira puramente objetiva:

\begin{abstract}
A lembrança representa numa ampla medida a reconstrução do passado com a ajuda de dados emprestados ao presente, inclusive preparada por outras reconstruções feitas em épocas anteriores e onde a imagem do passado foi bastante alterada (HALBWACHS, 1950, p. 38).
\end{abstract}

\title{
1.2. Movimentos e lugares (discursivos versus sociais)
}

Os movimentos discursivos podem ser vistos como maneiras de ocupar os lugares discursivos, enquanto atualização concreta dos papeis a serem desenvolvidos nessa situação. Esses lugares remetem à "mise en mots" das

\footnotetext{
${ }^{5}$ A expressão "mise en mots" aponta para a atividade de "escolha" das palavras e de sua colocação, que pode ser diferente de um locutor para o outro e de um momento para o outro para um mesmo locutor. A « mise en mots » não se concebe como um «decalque » do real, mas como um processo que comporta uma parte de criatividade ou pelo menos de especificidade da forma de dizer de um locutor. Nesse sentido, a noção de "mise en mots" está ligada a do "estilo discursivo" (FRANÇOIS, 1994, p. 265).
} 
EID\&A - Revista Eletrônica de Estudos Integrados em Discurso e Argumentação, Ilhéus, n. 11, jan/jun.2016.

representações que os interlocutores têm da situação, deles mesmos, do interlocutor, de suas relações recíprocas, dos temas a serem abordados ou não nessa situação, de expectativas mais ou menos divididas ligadas aos estatutos de uns e de outros num determinado enquadre interativo e social. Flahault (1978) e Vion (1999), na esteira de Goffman (1973 [1959]), insistiram, cada um à sua maneira, no fato de que os lugares sempre se situavam sempre em relação a um sentido pré-atribuído, mas que eles apenas se (re)produziam na interação hic e nunc. Em outros termos, uma grande parte do sentido préatribuído que os lugares podem aprovar ou rejeitar reside nos atributos ligados aos estatutos. Esses atributos (biológicos, sociais, experienciais, de conhecimento) implicam em diferenças ou semelhanças entre os interlocutores, e, dessa forma em um determinado número de assimetrias ou desigualdades (MARKOVÀ \& FOPPA, 1991). Para Flahault, toda palavra convoca o interlocutor a um lugar correlativo: a distribuição dos lugares é tributária do enquadre no qual ela se desenvolve e, de forma mais abrangente, do contexto social e cultural. A noção de lugar permite articular ${ }^{6}$ lugar do interlocutor na interação hic e nunc e o lugar desse mesmo interlocutor "na formação social a qual ele pertence" (FLAHAULT, 1978, p. 138).

Portanto, analisa-se uma produção discursiva muito além de um único ato discursivo isolado: ela é percebida como um encontro entre enunciadores que têm histórias conversacionais e sócio-discursivas diferentes e cujos traços são, em parte, identificáveis na materialidade linguajeira. Em relação a um mesmo discurso, nem todos percebem o mesmo dialogismo (compreendido aqui como um conjunto de vozes que o atravessam). Uma análise em termos de vozes não poderia ser, segundo o nosso ponto de vista, uma análise em termos de "componentes reais", mas sempre uma análise em termos de modos de interpretação.

\section{Quais são as fontes dos "conhecimentos" sobre si?}

Se é impossível constituir exaustivamente um inventário dessas fontes, iremos propor, contudo, eixos que diferenciem essas fontes. O discurso que fazemos sobre nos mesmos é muitas vezes intermediário entre o discurso objetivo do outro e o discurso subjetivo de si: pronunciar um discurso sobre si coloca, com efeito, o locutor na situação de um quase-outro que não é um

${ }^{6}$ Flahault entende que é no nível dessa articulação intermediária que se estabelece a identidade do indivíduo. 
EID\&A - Revista Eletrônica de Estudos Integrados em Discurso e Argumentação, Ilhéus, n. 11, jan/jun.2016.

verdadeiro outro. Toda pessoa pode falar de si retomando por sua própria conta o que o outro disse sobre ela (por exemplo, o que lhe contaram quando era criança, o que os médicos dizem obre ela), indicando simultaneamente ou alternativamente o que ela conhece de si por familiaridade (por exemplo, a percepção que ela tem de seu próprio caráter, de sua relação com os outros, mas também de seus receios, de suas esperanças, etc.). O conhecimento de si por "familiaridade" é do domínio de um saber "percebido" por si próprio e não transmitido pelo outro. Esse conhecimento de si "por familiaridade" nem sempre é explicitado ou colocado em palavras; no entanto, ele está muitas vezes estreitamente imbricado no discurso sobre si por um conhecimento que pertente a um saber transmitido pelo outro.

Entre os saberes transmitidos pelo outro sobre si, propomos distinguir:

- o saber relevante da doxa, como correspondente ao discurso do "a gente", ao "pronto para pensar" de uma coletividade. Trata-se de um discurso "que circula", como os provérbios, as fórmulas prontas, os slogans publicitários etc. Husserl definiu esse termo como um conjunto de crenças e de idéias não objetivas. Segundo Anscombre (1995, p. 39), uma doxa é determinada por topoi, os quais têm duas características centrais. De um lado, eles são "princípios gerais", nunca asseverados, mas empregados para servir de "apoio ao raciocínio". De outro lado, "eles podem ser inteiramente criados" e são muito frequentemente "apresentados como naturais". A sua existência é um fato sociológico, variável de uma cultura para a outra; além disso, como resume Sarfati (1997, p. 33), "dois topoi contrários podem coexistir numa mesma sociedade, num mesmo momento histórico (Quem se parece se junta / Os extremos se atraem)".

- o saber relevante do discurso especialista, corresponde ao conhecimento cientifico. Bakhtine $(1984)^{7}$ descreveu esse conhecimento como abstrato, impessoal, acarretando uma posição "objetiva” naquele que o detém.

\footnotetext{
7 Existe, no abstrato, a posição do terceiro que se identifica pela "posição objetiva" propriamente dita em relação com o "conhecimento científico". A posição do terceiro é totalmente justificada quando um indivíduo pode se colocar no lugar de outro indivíduo, onde os indivíduos são absolutamente intercambiáveis, o que é possível e fundado apenas nos casos onde se procura uma solução para problemas que não solicitem a pessoa em sua totalidade e sua não-reprodutibilidade, ou seja, lá onde o homem se especializa, expressando apenas uma parte destacada de seu todo, de sua pessoa, lá onde sua qualidade de "engenheiro", de "físico", etc., será substituída pelo seu eu (BAKHTINE, 1984, p. 364).
} 
EID\&A - Revista Eletrônica de Estudos Integrados em Discurso e Argumentação, Ilhéus, n. 11, jan/jun.2016.

- o saber relevante do outro como correspondente, especialmente, ao discurso relatado ou ao discurso do outro interiorizado. Bakhtine destacou a que ponto o saber sobre si mesmo é "determinado pela palavra pensada de um 'estrangeiro"' (BAKHTINE, 1970, p. 268). A análise que ele propõe da obra de Dostoievski caracteriza o discurso sobre si como atravessado pelo discurso moral dos outros:

O herói se julga em função da ideia que ele tem dos outros e da opinião de si que ele lhe atribui. A consciência de si é constantemente calcada pela consciência dos outros; o "eu por eu-mesmo" se refere constantemente ao "eu para os outros". É por isso que a palavra do herói sobre ele mesmo se constrói sob a influência incessante da palavra do outro ao seu respeito (Ibid., p. 269).

Uma consciência do outro sobre si, nem totalmente interior ou exterior a si, seria assim outra fonte maior de conhecimento sobre si. Essa grade de diferentes tipos de saberes sobre si, não exaustiva, pode, além disso, se articular, mais especificamente em relação ao discurso médico, distinguindo diversos tipos de relações entre saberes por familiaridade (ou percebidos) e saberes transmitidos (FRANÇOIS, 1995, p. 112):

- a grade em que as relações entre os saberes estão estabilizadas. Por exemplo, todos nós sabemos que "o Sol é maior do que a Lua", mesmo se não podemos percebê-lo: saberes percebidos e transmitidos não interferem entre si e não se opõem;

- a grade em que existe uma dominância (do ponto de vista do analista) de um desses saberes sobre o outro (como em "tenho medo de ter uma úlcera no estômago e é o médico quem me dirá se eu realmente tenho uma"). Mas essa oposição entre saber transmitido e saber percebido (sentido) nem sempre se resolve recorrendo à palavra "daquele que sabe", o que nos leva ao terceiro caso;

- a grade em que as relações entre esses saberes não podem ser estabilizados: é o que ocorre na entrevista aqui analisada, em que a própria voz do conhecimento de si por familiaridade (saber percebido) está constantemente em contato com a voz do saber do especialista. Como desenvolveu Clavreul:

[...] cada um sabe que existe um saber médico, que ninguém pode pretender possuir inteiramente, mas a quem sempre se pode recorrer. Além disso, o próprio doente nunca é um outro em relação a esse discurso. Ele participa desse discurso, ele é convidado a se juntar a ele, a se submeter a ele e, na realidade, ele o antecipa e tenta raciocinar sobre a sua doença em termos médicos (1978, p. 31). 
EID\&A - Revista Eletrônica de Estudos Integrados em Discurso e Argumentação, Ilhéus, n. 11, jan/jun.2016.

Essa doxa médica segundo a qual todo mal teria uma causa é, aliás, admitida por todos nós, pelo menos na cultura ocidental, juntando-se à própria doxa. Mas, como salienta Cicourel no âmbito do quadro de análise do raciocínio diagnóstico:

[...] os pacientes recorrem a um campo semântico particular ou restrito para traduzir as crenças nas quais eles acreditam e as aplicam no caso de sua doença - essas crenças, convém destacar, vão muitas vezes contra o ponto de vista do médico (2002, p. 66).

Cicourel analisa o fato de que o saber médico se insere em um sistema simbólico diferente daquele dos pacientes, privilegiando uma linguagem abstrata fundada em um sistema mnêmico externo de saberes objetivados que empregam "memórias externas" (dicionários de termos médicos, manuais de medicina, exames de laboratórios etc.). Isso exige do médico que "traduz" o discurso do paciente uma verdadeira "recodificação" para o estabelecimento de seu diagnóstico. Para Cicourel, os médicos deveriam explicitar melhor essa recodificação em suas comunicações com os pacientes: isso permitiria evitar certos mal entendidos, uma vez que os pacientes não raciocinam sobre a própria doença unicamente a partir de critérios objetivados, mas também, e sobretudo, a partir de saberes relevantes de crenças, as quais podem estar imbricadas com saberes mais especializados que circulam na vida social.

Destacaremos, nos trechos do corpus apresentados na última parte deste trabalho, as diferentes fontes de conhecimento sobre si evocadas pela entrevistada, distinguindo (mesmo que às vezes elas se sobreponham) as que são da ordem do saber sobre si:

- por familiaridade,

- pela doxa,

- por um discurso de especialista,

- por um discurso do meio de convivência,

- e os outros (esse último item nos permite insistir no fato de que a presente lista não pretende ser exaustiva).

Além isso, daremos a devida precisão na análise do grau de marcação da voz como "outra": os modos de marcação das vozes podem de fato ser analisados, seguindo a proposta de Volochinov (1977, p. 161ss) num continuum que vai de um pólo em que a voz se encontra "descolada" do discurso do 
EID\&A - Revista Eletrônica de Estudos Integrados em Discurso e Argumentação, Ilhéus, n. 11, jan/jun.2016.

enunciador (marcação "forte" de outra voz) até um pólo em que essa voz se encontra totalmente "integrada" (marcação fraca de outra voz) ${ }^{8}$.

\section{Comentários de trechos que veiculam diversas vozes explicativas da doença na entrevista de $\mathrm{F}$.}

Os trechos da entrevista que vamos comentar fazem parte de um corpus mais importante (quinze entrevistas) recolhidas junto a pessoas voluntárias que apresentam dependências variadas, colocando suas vidas em risco. Os entrevistadores desse conjunto de entrevistas, todos psiquiatras, procuravam entender "a conduta ordálica", assim definida:

[...] repetição de uma experiência que comporta algum risco mortal, na qual o sujeito se envolve, pela sua sobrevivência, para provar seu valor intrínseco, assim reconhecido pelas poderosas transcendências do Destino (CHARLESNICOLAS \& VALLEUR, 1982, p. 90).

Partindo dessa hipótese, os pesquisadores previram abordar, ao longo de entrevistas gravadas, conduzidas de forma semi-diretiva, os temas seguintes: risco ativamente buscado e vivido positivamente, condutas associadas que integram a vertente ordálica, psicotraumatismos e rupturas precoces, vivência desses acontecimentos. Antes da entrevista, os entrevistados, todos voluntários, receberam informações sobre os objetivos da pesquisa por meio de uma pré-entrevista oral e de uma carta escrita, resumida nos seguintes termos:

[...] fazer um trabalho de pesquisa acerca de eventos da vida (luto, perda, morte) e com a relação ao risco (dependência química, consumo excessivo de medicamentos psicotrópicos, disfunções das condutas alimentares, tentativas de suicídio etc. (VALLEUR, 1994, p. 182).

Entre as múltiplas implicações dialógicas ligadas ao contexto amplo e estreito desse corpus, podemos citar as seguintes: os discursos dos entrevistados foram necessariamente "pré-orientados" pela carta assim como pela pré-entrevista oral de apresentação da pesquisa; simultaneamente as hipóteses de pesquisa certamente influenciaram os entrevistadores na sua forma de reagir às falas dos entrevistados e mais globalmente em seu desempenho em seu papel de entrevistadores. Esse dialogismo interdiscursivo se desdobra no nível do dialogismo interlocutivo pelo fato de que os

${ }^{8}$ Para uma explicitação do ponto, confira Carcassonne (2010, p. 728ss). 
EID\&A - Revista Eletrônica de Estudos Integrados em Discurso e Argumentação, Ilhéus, n. 11, jan/jun.2016.

entrevistados sabiam que suas falas seriam objeto de reflexões de uma equipe de pesquisadores constituída por destinatários "no horizonte" (GADAMER, 1960; JAUSS, 1978) 9 do diálogo co-construído hic e nunc. Observemos como F. raciocina sobre a sua doença (no sentido de CICOUREL, 2002), em particular na sua forma de convocar diferentes tipos de vozes em seu discurso.

\subsection{Analise de três trechos}

A comparação de trechos produzidos em diferentes momentos da entrevista de F. coloca em evidência o movimento discursivo e argumentativo seguinte: para atenuar um discurso apresentado previamente como dóxico (primeiro trecho), F. começa por tomar algumas precauções (segundo trecho), parecendo dessa forma querer poupar as (supostas) convicções de seu interlocutor, segundo as quais os pais desempenhariam um papel na ocorrência da anorexia. Num segundo movimento discursivo (terceiro trecho), F. não demonstra mais as marcas de precaução anotadas no segundo trecho: no máximo, esse papel é admitido como uma confissão feita ao seu interlocutor. Esse movimento praticamente equivale a uma negação do papel dos pais na anorexia, enquanto que ela expressa outra explicação possível para a aparição de sua doença.

Vamos observar nesses três trechos representativos do conjunto da entrevista uma orquestração das diferentes vozes, assim como uma tensão entre essas vozes, pelo modo enunciativo presente na voz do "eu" (discurso sobre si por "familiaridade", "saber percebido") e na voz do outro (saber transmitido), no presente caso do discurso médico.

\subsubsection{Primeiro trecho}

A entrevista de F. começa desta forma:

1 comecei a ficar gravemente anoréxica com quatorze anos logo após minha puberdade

2 bem, a origem exata eu ainda busco até hoje

3 eu penso que há um conflito, como sempre, com meus pais

4 mas sobretudo eu não gostava de meu corpo

\footnotetext{
${ }^{9}$ A perspectiva de Jauss (1978, p. 284) era a de uma interpretação dos textos literários; ela pode, no entanto, ser aplicada, como as de Volochinov \& Bakhtin, a discursos produzidos em interação. Jauss formulou a ideia segundo a qual só se pode entender um texto se entendermos a que pergunta ele responde; e só se pode reconstituir essa pergunta operando uma fusão sincrônica de dois horizontes de espera: um anterior ao texto e outro que o texto faz aparecer. Ele se inspirou em Gadamer (1960) que propunha uma fusão diacrônica dos horizontes.
} 
EID\&A - Revista Eletrônica de Estudos Integrados em Discurso e Argumentação, Ilhéus, n. 11, jan/jun.2016.

Em 1, a afinidade entre a avaliação "gravemente" e a menção temporal "logo após minha puberdade" fazem ressoar o gênero discursivo "anamnese médica", portanto uma voz de especialista. Essa voz se reveste ao mesmo tempo de uma forma de mise en scène de si na medida em que F. mostra ao seu entrevistador bem como àqueles que lerão mais tarde suas falas transcritas que ela é capaz de falar de si mesma como um médico falaria.

Em 2, inicia-se a voz da doxa médica que vai permear a totalidade da entrevista, com a expressão de "origem exata" (desvinculada em nível enunciativo).

Em 3, com a expressão "eu penso", o plano enunciativo do tipo "discurso" continua a ser dominante mesmo se notamos que o movimento de desancoragem enunciativa, iniciado em 2, prossegue, movimento que veicula, por sua vez, a voz da doxa médica. Esse movimento de desancoragem é identificável a partir dos seguintes elementos: o apresentativo há, o termo anorexia, a ausência de possessivos, a expressão como sempre. Esses elementos dão ao conteúdo desse enunciado um alcance de verdade geral (absoluta) e F. se apresentando como aderindo a essa voz genérica. Com o emprego do indefinido "um" ("um conflito") e o verbo do discurso introdutório "eu penso", a voz da doxa médica (intermediária entre o discurso do "a gente" e o discurso do especialista) se reveste da voz individual de F.: como salientou Martin (1983, p. 155), "o enunciado universal construído com "um" aponta muitas vezes para o lado da experiência particular (pessoal). Se a gente diz que um bom vinho não faz mal, tem-se em vista, por exemplo, a indiferença que a garrafa de vinho que lhe ofereço não lhe fará mal”'10).

Em 4, F. se apresenta não somente como alguém que é capaz de assimilar as teorias "psi", mas também de modulálas, como aponta o marcador "mas sobretudo" que introduz uma outra explicação da origem da anorexia, relevando desta vez de uma fonte pertencente à voz de seu "personagem" no passado (plano "anafórico" "1). Essa voz é a da esfera do conhecimento de si por "familiaridade"; ela é aqui apresentada como um argumento superior ao anterior para explicar a origem da anorexia.

${ }^{10}$ Esse exemplo, no entanto, talvez não seja tão generalizável hoje como nos anos 1980, com a doxa sobre esse tema tendo evoluído nesses últimos anos.

11 Para uma explicitação das diferenças entre planos "anafóricos", "dêiticos" e "indeterminados", confira Carcassonne (2015, p. 112ss) 
EID\&A - Revista Eletrônica de Estudos Integrados em Discurso e Argumentação, Ilhéus, n. 11, jan/jun.2016.

\subsubsection{Segundo trecho}

Um pouco mais adiante na entrevista, F. conta que veio para Paris para seus estudos de nutricionista:

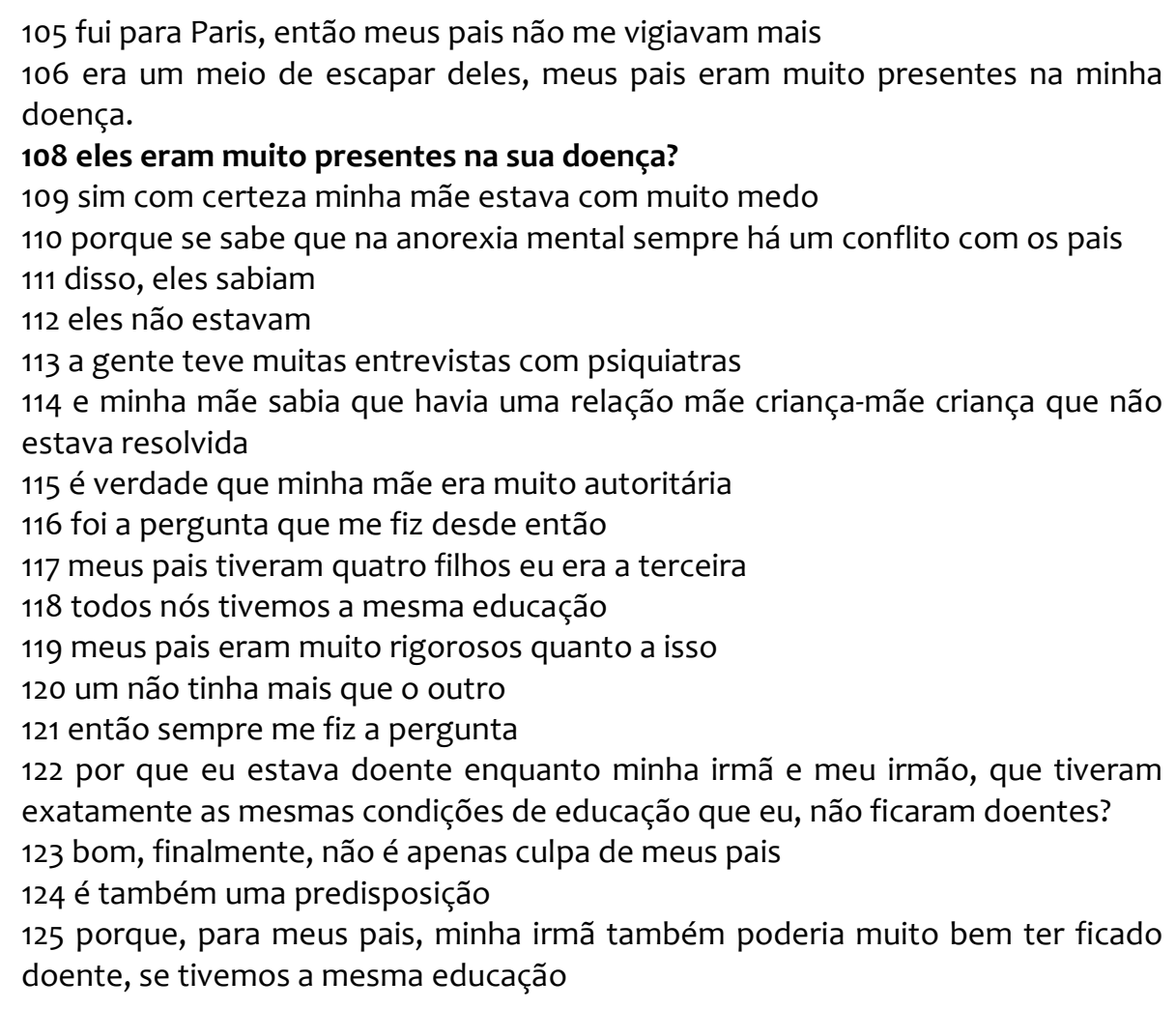

F. apresenta nesse trecho duas causas eventuais da anorexia: seus pais e uma predisposição.

\section{3·3.2.1 Primeira causa: os pais}

Essa causa é apresentada, de início, como pertencente a um discurso transmitido por um indefinido "se" em 110 ("porque se sabe que na anorexia mental sempre há um conflito com os pais"). Esse enunciado remete muito claramente ao enunciado 3 "eu penso que há um conflito, como sempre, com os pais". No entanto, o conflito "das origens" que existia nesse enunciado 3 entre "eu penso" (discurso do "eu") e "como sempre" (discurso da doxa médica) não aparece mais nesse enunciado 110: aqui, a origem é dada unicamente como sendo a do discurso do "se", com a utilização do "se sabe que". O enunciado 111, tematização da proposição anterior pelo viés da repetição anafórica de "isso" (em “disso, eles sabiam”), tem como efeito insistir no fato de que F. aceita esse discurso do "se" mesmo querendo minimizá-lo. A 
EID\&A - Revista Eletrônica de Estudos Integrados em Discurso e Argumentação, Ilhéus, n. 11, jan/jun.2016.

causa "os pais" (como sendo a origem da anorexia) é em seguida apresentada como pertencente a um discurso transmitido pelos psiquiatras: "a gente teve muitas entrevistas com psiquiatras e minha mãe sabia que tinha uma relação mãe criança-mãe criança que não estava resolvida".

Nota-se um leve deslocamento de categoria no sentido de que, após invocar seus pais enquanto responsáveis da anorexia em 110, F. não evoca mais a sua mãe em 114. Nos dois casos, é o discurso relatado do outro como especialista que faz a ligação entre o discurso experiencial do eu e o discurso genérico do "se". A essa causa (que retoma a voz do discurso médico e pertence então ao saber transmitido), F. acrescenta outro discurso que pertencente ao seu autoconhecimento "por familiaridade", o discurso da predisposição.

\subsubsection{Segunda causa: uma predisposição}

F. toma claramente todas as precauções para invocar essa causa mais pessoal. Ela não expressa de imediato seu ponto de vista, mas o apresenta sob forma de pergunta (enunciado 122), a qual é introduzida por dois enunciados metadiscursivos em 116 e 121:

116 foi a pergunta que me fiz desde então 121 então sempre me fiz a pergunta

122 por que eu estava doente enquanto minha irmã e meu irmão, que tiveram exatamente as mesmas condições de educação que eu, não ficaram doentes?

O advérbio sempre do enunciado 121 pressupõe que $F$. não tem resposta para essa pergunta. Essa pergunta pode ser qualificada como citação emblemática de atitude. F. apresenta um pano de fundo para compreender a pergunta que ela fez a si própria (enunciados 117 a 120):

\footnotetext{
117 meus pais tiveram quatro filhos eu era a terceira

118 todos nós tivemos a mesma educação

119 meus pais eram muito rigorosos quanto a isso

120 um não tinha mais que o outro

123 bom, finalmente, não é apenas culpa de meus pais

124 é também uma predisposição
}

Em 123 e 124, F. dá uma resposta à pergunta que se apresentava sem solução em 121 e 122. A justaposição desses dois grupos de enunciados deixa implícito que se trata de uma "eventual" resposta a esta pergunta. $O$ discurso particular e experiencial anterior (117-122) chega aqui a uma conclusão de cunho pessoal que se opõe ao discurso especializado dos psiquiatras 
EID\&A - Revista Eletrônica de Estudos Integrados em Discurso e Argumentação, Ilhéus, n. 11, jan/jun.2016.

(apresentado em 110-114). A rapidez da alternância entre essas diferentes vozes traz uma explicação caracterizada por seu modo de pulsação: trata-se aqui da análise dos movimentos de fonte enunciativa, e não dos tempos verbais, que permite caracterizar o discurso de $\mathrm{F}$.

Os termos introdutores "bom" e "finalmente" estão em sintonia para introduzir a "reconsideração" de F. em relação ao julgamento expresso anteriormente e apresentado como relevante da doxa ("tive anorexia por causa de meus pais"): eles desempenham tanto um papel de conector argumentativo quanto de modalização. F. faz uma reconsideração da doxa, mas de forma tímida. De um lado, essa reconsideração é apresentada como uma eventual resposta a uma pergunta. Por outro lado, afora os termos introdutores "bom" e "finalmente", essa reconsideração não traz marcas enunciativas explícitas (do tipo "eu penso que"): é o movimento discursivo entre os enunciados anteriores (116 a 122) e estes (123 e 124) que permite determinar a fonte enunciativa dessa reconsideração.

Em 125, F. explicita o movimento de pensamento que the permite modificar o julgamento apresentado anteriormente como dóxico: 125 "porque, para meus pais, minha irmã também poderia muito bem ter ficado doente, se tivemos a mesma educação".

Esse enunciado 125 retoma, a distância, os enunciados 118, 120 e 122: um efeito de insistência é obtido e reforçado (de modo discreto) pelas modalizações (condicional de "poderia", advérbio "bem") que são reforçados pelo intensificador "muito".

O enunciado 115 "é verdade que minha mãe era muito autoritária" - no qual F. formula, igualmente, um julgamento em que esconde a fonte enunciativa do enunciado - reforça o fato segundo o qual $F$. explicita mais facilmente as fontes enunciativas pertencentes à doxa (enunciado 110) do que aquelas ligadas ao "eu".

\subsubsection{Terceiro Trecho}

Mais adiante na entrevista, F. demonstra diversas vezes estar em continuidade consigo mesma e consegue, com distância, expor a sua "própria versão" da origem da anorexia. Ela vai, ao mesmo tempo, demonstrar certa segurança ao criticar a doxa médica e marcar sua voz de conhecimento de si pela familiaridade mais adequada para explicar a origem de sua anorexia. 
EID\&A - Revista Eletrônica de Estudos Integrados em Discurso e Argumentação, Ilhéus, n. 11, jan/jun.2016.

Nesse segundo trecho, nota-se um movimento argumentativo similar, no que tange ao nível de desencadeamentos dos argumentos, ao que acaba se ser comentado.

\author{
169 mas frequentemente eu sentia um tipo de nostalgia durante as férias. \\ 170 eu me entediava \\ 171 eu dizia para a mamãe que eu me entediava \\ 172 ela me diz por quê \\ 173 porque não estou na escola, fazemos sempre as mesmas coisas \\ 174 e não sabia não sabia se eram os pais que \\ 175 ou se era meu estado de espírito pessoal \\ 176 eu sentia que eu tinha uma certa melancolia no espírito que não ia bem \\ 177 e depois fiquei doente e sinto as mesmas impressões \\ 178 então penso que exista dessa forma \\ 179 bem tem a educação dos meus pais \\ 180 mas existe, de todo modo, uma personalidade pessoal em mim, algo \\ profundo em mim que me fez desenvolver essa doença
}

Novamente, F. admite a "doxa" médica segunda a qual seus pais estariam na origem de sua anorexia (em 174) para apresentar em seguida sua própria explicação (178-180), explicação que pertence (176-177) a um conhecimento percebido e não transmitido.

Nota-se, no entanto, diferenças na apresentação dos argumentos:

- a doxa médica é mais lentamente admitida. De fato, o papel dos pais é apresentado primeiro de maneira muito hipotética em 174 para em seguida ser admitido como uma concessão em 179, o que está marcado por meio do conector-modalizador "bom" (empregado, no entanto, de forma muito próxima ao enunciado 123, conforme 3.3.2);

- a própria versão de F. é apresentada de forma lógica e "objetivada" graças a um efeito produzido pelo conector "então" em 179.

- o saber de si pela familiaridade (o tédio) é veiculado pelas citações emblemáticas de atitudes $(171,173)$ apresentadas como respostas a uma pergunta da mãe ("por quê"), evocando no presente um diálogo passado: esse processo reforça de fato a orquestração das vozes no discurso de $F$.

A presença do conector "mas" e da modalização "de todo modo" estão em sintonia para dar ao enunciado de F. um valor de contra-argumento em relação à doxa médica. Eles marcam a fonte dessa voz como pertencente a um conhecimento percebido (e não transmitido), isso num plano enunciativo intermediário entre o plano dêitico e o plano indeterminado (por conta de 
EID\&A - Revista Eletrônica de Estudos Integrados em Discurso e Argumentação, Ilhéus, n. 11, jan/jun.2016.

uma relativa desancoragem enunciativa com o apresentativo "há" e o presente genérico).

Contra-argumentando em relação ao que ela acredita ser uma doxa médica, F. parece querer, ao mesmo tempo, poupar as convicções de seu interlocutor e mostrar a imagem de alguém que detém esse saber.

\section{Conclusão}

No conjunto desses três trechos, F. propõe argumentos e contraargumentos que se apresentam como vozes para justificar o fato de que seus pais não são os únicos responsáveis pelo aparecimento de sua anorexia. Ela cita seus pais como causa eventual dentro de um movimento discursivo bem particular: primeiro, ela apresenta esse fato como proveniente da doxa, ou seja, como um fato que todos conhecem, inclusive o seu interlocutor. Em seguida, ela retoma esse argumento acrescentando uma primeira nuance que poderia se apresentar da seguinte forma: "Não são apenas os meus pais que estão na origem da anorexia, existe também uma predisposição pessoal". Esse argumento pessoal é previamente justificado por um discurso particular e experiencial. Ao discurso transmitido pertencente à doxa médica (110-114, 174, 179), F. contrapõe um discurso pessoal (123-124,180), o qual se justifica por um discurso particular e experiencial pertencente a um conhecimento de si "por familiaridade" (117-122, 169-177), que nos consideramos como uma voz entre outras vozes.

F. se apresenta, assim, como alguém que sabe adotar uma posição crítica em relação ao saber transmitido (pertencente ao discurso médico e mais geralmente ao dos demais). Suas diferentes propostas de interpretação do comportamento anoréxico mostram ao interlocutor, ele próprio médico e pesquisador, uma interferência de suas "pré-ocupações" enquanto entrevistador.

As diferentes vozes empregadas por F. correspondem, além de tudo, a lugares discursivos que podem ser percebidos simultaneamente como lugares sociais: a voz do conhecimento de si pela familiaridade, original na medida em que aparece como a única voz que permite falar de si sem tomar nada emprestado dos outros, adquire aqui uma forma de legitimidade quando colocada em relação com as outras, mais especificamente a que atribui aos médicos. A reiterada introdução desta voz muito pessoal (assumida no nível enunciativo de modo fraco, mas, no entanto, claramente atualizada), para "concorrer" com a voz médica, modifica fortemente a assimetria social esperada numa interação entre médico e não médico: a orquestração das vozes 
EID\&A - Revista Eletrônica de Estudos Integrados em Discurso e Argumentação, Ilhéus, n. 11, jan/jun.2016.

por F. tem finalmente uma função argumentativa e de mise en scène positiva de si. Essa orquestração desempenha claramente um papel de reposicionamento social no espaço de suspensão pontual permitida na e pela entrevista.

\section{Referências}

ANSCOMBRE, Jean-Claude. Théorie des topoï. Paris: Kimé, 1995

BAKHTINE, Mikhaïl. Esthétique de la création verbale. Paris: Gallimard, 1984 [1979].

. La poétique de Dostoïevski. Paris: Seuil, 1970 [1963].

BRES, Jacques. Savoir de quoi on parle: dialogue, dialogal, dialogique; dialogisme, polyphonie. In: BRES, Jacques; HAILLET, Patrick Pierre; MELLET, Sylvie; NØLKE, Henning; ROSIER, Laurence (Éds.). Dialogisme et polyphonie. Approches linguistiques. Bruxelles: De Boek Duculot, 2005. p. 47-61.

; NOWAKOWSKA, Aleksandra. Dialogisme: du principe à la matérialité discursive. Recherches linguistiques, n. 28, p. 143-164, 2006.

CARCASSONNE, Marie. Présentation de soi dans l'entretien clinique: narration, explication, interprétation. In: GROSSEN, Michèle; SALAZAR ORVIG, Anne (Dirs.). L'entretien clinique en question: analyse des interactions d'un genre communicatif hétérogène. Paris: Belin, 2006. p. 213-231.

- Entretiens de recherche en psychopathologie: une approche par les mouvements de genres. Langage \& Société, n. 123, p. 87-103, 2008.

- Les voix dans un entretien de recherche: quelles marques et quelles

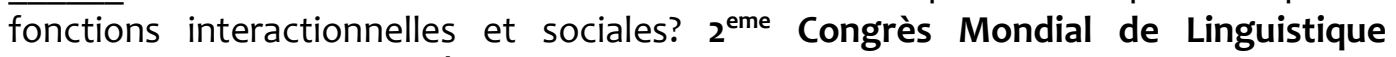
Française - CMLF. Actes (Éds. Franck Neveu, Valelia Muni Toke et al). New Orleans, USA. Disponível em: http://dx.doi.org/10.1051/cmlf/2010076.

. Quelles sont les significations dessinées par le dialogisme ? Une perspective en analyse de discours. Colloque International Dialogisme: langue, discours. Actes (Coord. Jacques Bres, Aleksandra Nowakowska et al). Montpellier, France, Septembre 2010. Disponível em : http://basepub.dauphine.fr/handle/123456789/7799.

- Analyse discursive de points de vue dans des récits de parcours professionnels extraits d'entretiens. In: FRANÇOIS, Frédéric; CARCASSONNE, Marie; CUNHA, Dóris; DONAHUE, Christiane; RABATEL, Alain. Points de vue sur le point de vue. Limoges : Lambert-Lucas, 2015. p. 77-167.

CHARLES-NICOLAS, Aimé; VALLEUR, Marc. Les conduites ordaliques. In: OLIEVENSTEIN, Claude. La vie du toxicomane: Séminaire de l'hôpital Marmottan. Paris: P.U.F., 1982. p. 82-99. 
EID\&A - Revista Eletrônica de Estudos Integrados em Discurso e Argumentação, Ilhéus, n. 11, jan/jun.2016.

CICOUREL, Aaron. Le raisonnement médical. Paris: Seuil, 2002.

CLAVREUL, Jean. L'ordre médical. Paris: Seuil, 1978.

CLOT, Yves. La fonction psychologique du travail. Paris: P.U.F., 1999.

COLE, Michael. A conception of culture for a communication theory of mind. In: VOCATE, Donna R (Ed.). Interpersonal Communication. Different voices, different minds. Erlbaum: Hillsdale, 1994.

FLAHAULT, François. La parole intermédiaire. Paris: Seuil, 1978.

FRANÇOIS, Frédéric. Interprétation linguistique et psychopathologie. L'Evolution psychiatrique, tome 49, fascicule 2, p.15-450, 1984.

. De quelques aspects du dialogue psychiatre-patient. Places, genres, mondes et compagnie. C.A.L.A.P., n.5, p.39-89, 1989.

. Pratiques de l'oral. Paris: Nathan, 1993.

. Morale et mise en mots. Paris: L'Harmattan, 1994.

- Quelques remarques sur la notion d'interprétation ou du dialogue quotidien comme modèle d'interprétation. Cahiers de I'ILSL, n.6, p. 97-129, 1995.

. Essais sur quelques figures de l'orientation; hétérogénéités, mouvements et styles. Paris: Lambert-Lucas, 2009.

GADAMER, Hans George. La compréhension dans les sciences humaines. In: Vérité et méthode. Paris: Seuil, p.103-226, 1960.

GOFFMAN Erving. La mise en scène de la vie quotidienne. Tome I: La présentation de soi. Paris, Minuit, 1973 [1959].

HALBWACHS, Maurice. La mémoire collective. Disponível em: http://classiques.uqac.ca/classiques/Halbwachs_maurice/memoire_collective/memoir e_collective.html

JAUSS, Hans Robert. Pour une esthétique de la réception. Paris: Seuil, 1978.

MARKOVÀ, Ivana. Dialogicité et représentations sociales. Paris: P.UF. , 2007 [2003]).

; FOPPA, Klaus (Eds). Asymmetries in dialogue. New York: Harvester, 1991.

MARTIN, Robert. Pour une logique du sens. Paris: P.U.F., 1983.

ROGOFF, Barbara. Apprenticeship in thinking. Cognitive development in social context. New York: Oxford University Press, 1990. 
EID\&A - Revista Eletrônica de Estudos Integrados em Discurso e Argumentação, Ilhéus, n. 11, jan/jun.2016.

SALAZAR ORVIG, Anne. Les mouvements du discours. Style référence et dialogue dans des entretiens cliniques. Paris: L'Harmattan, 1999.

. La notion de déplacement dans une approche dialogique du dialogue. In: DELAMOTTE-LEGRAND, Régine; HUDELOT, Christian; SALAZAR-ORVIG, Anna (Éds). Dialogues, mouvements discursifs, significations. Cortil-Wodon: E.M.E., 2008. p.15-30.

SARFATI, George Elia. Eléments d'analyse de discours. Paris, Nathan, 1997.

SCHNEUWLY, Bernard. Genres et types de discours. In: REUTER, Yves (Éd). Les interactions lecture-écriture. Berne: Peter Lang, 1994. p. 155-174.

VALLEUR, Marc. Toxicomanie et mort - addictions et conduites de risque. Rapport de Recherche pour le Ministère de l'Enseignement Supérieur et de la Recherche. G.R.E.C.O. Paris, 1994. http://www.hopital-marmottan.fr/publications/GRECO\%20\%20toxicomanie\%20et\%2omort.pdf

VION, Robert. Pour une approche relationnelle des interactions verbales et des discours. Langage \& Société, n. 86, p.95-129, 1999.

VOLOCHINOV, Valentin (BAKHTINE, Mikhail). Le Marxisme et la philosophie du langage.. Paris: Minuit. 1977 [1929].

VYGOTSKI, Lev Semionovitch. Pensée et Langage. Paris: Éditions sociales, 1985 [1934].

WERTSCH, James V. Voices of the mind: a sociocultural approach to mediated action. Cambridge: Harvard University Press, 1991.

Tradução:

Frédéric Robert Garcia

Docente da Univesidade Estadual de Santa Cruz

Revisão da tradução:

Eduardo Lopes Piris

Docente da Univesidade Estadual de Santa Cruz

Forma de citação sugerida:

CARCASSONNE, Marie. Uma argumentação pela orquestração das vozes numa entrevista ou como rebater uma doxa médica com suavidade. Trad. Frédéric Robert Garcia. Rev. Trad. Eduardo Lopes Piris. EID\&A - Revista Eletrônica de Estudos Integrados em Discurso e Argumentação, Ilhéus, n. 11, p. 55-73, jan/jun.2016.

Recebido em: 10/04/2016

Aprovado em: 11/05/2016 